\title{
ENRAIZAMENTO IN VITRO DE PORTA-ENXERTOS DE Prunus ${ }^{l}$
}

\author{
MARCELO ROGALSKI ${ }^{2}$, LIZIANE KADINE ANTUNES DE MORAES ${ }^{3}$, CLAUDIA FESLIBINO $^{4}$, LEANDRO \\ CRESTANI $^{5}$, MIGUEL PEDRO GUERRA ${ }^{6}$, APARECIDO LIMA DA SILVA $^{7}$
}

\begin{abstract}
RESUMO - Na micropropagação de Prunus sp., o enraizamento tem sido considerado uma fase crítica, pois determina a sobrevivência das plantas durante a aclimatização. Dentre os fatores importantes ao enraizamento in vitro, destacam-se o genótipo e as auxinas por serem determinantes na indução e na formação de raízes. O objetivo deste trabalho foi avaliar o efeito de diferentes concentrações de IBA no enraizamento in vitro dos portaenxertos de espécies do gênero Prunus: cultivares Capdeboscq e GF677, e seleções VP411 e VP417. Para o enraizamento in vitro, brotos com 2-3cm de comprimento foram introduzidos em meio de Lepoivre suplementado com 0,$1 ; 0,5 ; 1,0$ e 2,0 mg.L $\mathrm{L}^{-1}$ IBA. Observou-se que o porta-enxerto 'Capdeboscq' apresentou maior taxa de enraizamento e maior número de raízes in vitro, sendo superior aos demais genótipos quanto a estas características. O nível de 1,0 mg.L $\mathrm{L}^{-1}$ de IBA esteve associado à maior taxa média de enraizamento (100\%, 64\% e 64,0\%, respectivamente) para os porta-enxertos 'Capdeboscq', 'GF677' e VP411. O nível de 2,0 mg.L $L^{-1}$ de IBA foi superior para a seleção VP417 com taxa de $64 \%$ de enraizamento. Para os porta-enxertos 'Capdeboscq' e 'GF677', o número máximo de raízes foi de 9,6 e 5,2 raízes por broto, respectivamente, em resposta ao nível de 2,0 mg.L L $^{-1}$ de IBA, enquanto as seleções VP411 e VP417 apresentaram o maior número de raízes (3,6 e 3,9, respectivamente) em resposta ao nível de 1,0 mg.L-1 de IBA.
\end{abstract}

Termos para indexação: Pessegueiro, IBA, rizogênese, micropropagação, genótipo.

\section{IN VITRO ROOTING OF PRUNUS ROOTSTOCKS}

ABSTRACT - In Prunus sp. micropropagation of rooting is considered a critical stage, since it determines the plant survival during the acclimatization. Among important factors associated with rooting, the genotype and the auxins are considered important in the induction and formation of roots. The objective of the present work was to evaluate the effect of different IBA on the in vitro rooting of Prunus rootstocks Capdeboscq and GF677, and the selections VP411 and VP417. For the in vitro rooting stage, shoots of 2-3cm long were inoculated in Lepoivre's medium supplemented with IBA $\left(0.1,0.5,1.0\right.$ and $\left.2.0 \mathrm{mg} . \mathrm{L}^{-1}\right)$. The results showed that the rootstock Capdeboscq presented the highest in vitro rooting rate as well as root number per shoot. The level of $1.0 \mathrm{mg} . \mathrm{L}^{-1}$ of IBA was associated with rooting rates of $100 \%, 64 \%$ and $64 \%$ for the rootstocks Capdeboscq, GF677 and VP411, respectively. The level of $2.0 \mathrm{mg} . \mathrm{L}^{-1}$ of IBA was associated with rooting rates of $64.0 \%$ for the selection VP417. For the rootstocks Capdeboscq and GF677, the highest root number per shoot was 9.6 and 5.2, respectively in response to the level $2.0 \mathrm{mg}^{-L^{-1}}$ of IBA. As for the selections VP411 and VP417 the highest root number (3.6 and 3.9; respectively) was observed in response to the level $1.0 \mathrm{mg} . \mathrm{L}^{-1}$ of IBA.

Index terms: Peach tree, IBA, rhizogenesis, micropropagation, genotype.

\section{INTRODUÇÃO}

A qualidade genética e sanitária das mudas é fator determinante para o sucesso da atividade frutícola, pois afeta diretamente a produtividade e a qualidade dos frutos. A produtividade das prunáceas é negativamente afetada pela falta de mudas certificadas e a inexistência de sistemas de controle na produção de materiais básicos e certificados, possibilitando a infecção e a disseminação de vírus e assemelhados nos pomares (Fachinello, 2000).

Neste contexto, para a produção de mudas livres de doenças e pragas, torna-se prioridade a definição de porta-enxertos adaptados às condições de solo e clima. Os porta-enxertos devem ainda apresentar vigor definido e crescimento uniforme. Assim, é fundamental o desenvolvimento de novas alternativas de porta-enxertos, preferencialmente clonais, em substituição aos tradicionais (Damiano \& Palombi, 2000; Fachinello, 2000).

Para a produção clonal de porta-enxertos de frutíferas, a micropropagação é uma técnica com aplicação crescente, principalmente para diferentes espécies de Prunus (Campana et al., 1994; Harada \& Murai, 1996; Damiano \& Palombi, 2000; Pérez-Tornero et al., 2000).

Na propagação in vitro de Prunus sp., a rizogênese é considerada uma fase crítica, pois determina o sucesso na aclimatização, ou seja, a transição das condições in vitro para ex vitro. Têm sido constatados problemas pelo fato de que raízes formadas in vitro são morfologicamente normais, mas podem apresentar distúrbios fisiológicos (Filiti et al., 1987).

A indução de raízes no gênero Prunus sp. pode ser afetada por uma interação de fatores, destacando-se o genótipo (Pevalek-Kozlina \& Jelaska, 1987; Caboni et al., 1997), o meio de cultura (Skirvin et al., 1982;
Dimassi-theriou, 1995) e os reguladores de crescimento, dentre os quais, as auxinas são determinantes para o sucesso no enraizamento in vitro (Campana et al., 1994; Harada \&Murai, 1996; Deklerk et al., 1997; PérezTornero et al., 2000).

No presente trabalho, avaliou-se a capacidade rizogenética in vitro dos porta-enxertos para espécies do gênero Prunus: cultivares Capdeboscq e GF677, e das seleções VP411 e VP417 em resposta a diferentes concentrações de ácido indolbutírico (IBA).

\section{MATERIALEMÉTODOS}

Os porta-enxertos 'Capdeboscq' (Prunus persica (L.) Batsch), 'GF677' (Prunus amygdalus x Prunus persica) e as seleções da variedade de Capdeboscq VP411 e VP417 (porta-enxertos obtidos pela Vitroplanta - Biotecnologia Ltda), foram estabelecidos in vitro a partir de plantasmatrizes mantidas em casa de vegetação no Departamento de Fitotecnia, Centro de Ciências Agrárias (CCA) da Uuniversidade Federal de Santa Catarina (UFSC) e na Vitroplanta Ltda, município de Videira, Estado de Santa Catarina.

Para a multiplicação e alongamento das brotações, utilizou-se o meio de cultura dupla-fase, constituído de sais e vitaminas de Lepoivre (Quoirin et al., 1977), suplementado com sacarose (20,0 g.L-1 ), ágar (7,0 g.L $\mathrm{L}^{-1}$ ) e $0,5 \mathrm{mg} . \mathrm{L}^{-1}$ de 6-benzilaminopurina (BAP), na fase sólida. Após 15 dias de cultura in vitro, foi adicionado o meio líquido de composição igual ao citado anteriormente, porém isento de BAP. O pH do meio de cultura foi ajustado para 5,2-5,3 antes da autoclavagem a $121^{\circ} \mathrm{C}$, durante 15 minutos.

Para o enraizamento in vitro, as microestacas com 2 a $3 \mathrm{~cm}$ de

${ }^{1}$ (Trabalho 161/2002). Recebido: 25/10/2002. Aceito para publicação: 18/07/03.

${ }^{2}$ Biólogo, Mestre, Universidade Federal de Santa Catarina, Departamento de Fitotecnia, C.P. 476, 88040-900, Florianópolis-SC, (48) 331-5330.

${ }^{3}$ Acadêmica em Agronomia da Universidade Federal de Santa Catarina, C.P. 476, 88040-900, Florianópolis-SC, (48) 331-5330, bolsista RHAE/CNPq.

${ }^{4}$ Acadêmica em Biologia da Universidade do Oeste de Santa Catarina, C.P. 187, 89560-000, Videira-SC, (49) 551-1422, bolsista RHAE/CNPq.

${ }^{5} \mathrm{Eng}^{\mathrm{o}}$. Agr ${ }^{\circ}$. Empresa Vitroplanta - Biotecnologia Ltda, C.P. 150, 89.560-000, Videira-SC, (49) 566-2690, bolsista RHAE/CNPq.

${ }^{6}$ Professor Titular da Universidade Federal de Santa Catarina, Departamento de Fitotecnia, C.P. 476, 88040-900, Florianópolis-SC, (48) 331-5330.

${ }^{7}$ Prof. Adjunto da Universidade Federal de Santa Catarina, Departamento de Fitotecnia, C.P. 476, 88040-900, Florianópolis-SC, (48) 331-5330, alsilva@ @cca.ufsc.br. 
comprimento foram introduzidas em meio de enraizamento contendo sais e vitaminas de Lepoivre (Quoirin et al., 1977) suplementado com sacarose (20,0 g.L $\left.\mathrm{L}^{-1}\right)$, ágar (7,0 g.L $\left.\mathrm{L}^{-1}\right)$ e ácido indolbutírico (IBA) nas concentrações de 0,$1 ; 0,5 ; 1,0$ e 2,0 mg.L $\mathrm{L}^{-1}$.

$\mathrm{O}$ experimento foi conduzido em câmara de crescimento com temperatura de $25 \mathrm{r} 2^{\circ} \mathrm{C}$, fotoperíodo de 16 horas e intensidade luminosa de 40-45Pmol. $\mathrm{m}^{-2} \cdot \mathrm{s}^{-1}$, fornecida por lâmpadas fluorescentes brancas frias.

O delineamento experimental adotado foi o inteiramente ao acaso, em esquema fatorial $4 \times 4$ : Fator A foi composto por quatro genótipos (Capdeboscq, GF677, VP411 e VP417) combinados com quatro concentrações de IBA $\left(0,1 ; 0,5 ; 1,0\right.$ e 2,0 mg. $\left.\mathrm{L}^{-1}\right)$. Cada unidade experimental foi constituída por cinco microestacas e repetida cinco vezes. Os dados referentes à porcentagem de enraizamento e número de raízes foram coletados aos 15 dias, em cultura in vitro. Estes dados foram submetidos à análise de Variância (ANOVA) e ao teste de comparação de médias SNK (5\%). Os dados médios referentes aos efeitos das concentrações de IBA para cada genótipo foram submetidos à análise de regressão, conforme recomendação de Sokal \& Rohlf (1995).

\section{RESULTADOSE DISCUSSÃO}

$\mathrm{Na}$ fase inicial de enraizamento, o surgimento dos primórdios radiculares não foi uniforme, ocorrendo variações entre os genótipos e os níveis de IBA. Para o porta-enxerto 'Capdeboscq', a rizogênese foi mais precoce que os demais genótipos ('GF677'; VP411 e VP417). Cinco dias após o início do experimento, observaram-se protuberâncias na base dos explantes e, após sete dias, visualizaram-se pequenas raízes. Resultados similares foram observados no enraizamento in vitro de Prunus insititia (Perelman \& Caso, 2000). Verificou-se também, no presente trabalho, que as concentrações de IBA de 0,$5 ; 1,0$ e 2,0 mg.L $\mathrm{L}^{-1}$ aceleraram a rizogênese, enquanto, na concentração de $0,1 \mathrm{mg} . \mathrm{L}^{-1}$, houve um retardo no enraizamento.

A porcentagem de enraizamento e o número de raízes foram significativamente afetados pelo genótipo, pela concentração de IBA e pela interação genótipo x concentração de IBA. Os porta-enxertos apresentaram diferentes respostas para a porcentagem de enraizamento com relação aos níveis de IBA testados (Tabela 1). O porta-enxerto 'Capdeboscq' foi superior aos demais genótipos quanto à taxa de enraizamento (100\%) na concentração de $1,0 \mathrm{mg} . \mathrm{L}^{-1}$, de IBA, seguido pela cultivar GF677 (64\% e 60\%) e as seleções VP411 (64\% e 52\%) e VP417 (56\% e 64\%) nas concentrações de 1,0 e 2,0 mg.L ${ }^{-1}$ de IBA, respectivamente.

TABELA 1 - Porcentagem de enraizamento in vitro de quatro portaenxertos de Prunus ('Capdeboscq', 'GF677', VP417 e VP411), referente ao uso de quatro níveis de IBA $(0,1 ; 0,5$; 1,0 e 2,0 mg. $\left.\mathrm{L}^{-1}\right)$, avaliação após 15 dias de cultura in vitro. UFSC, Florianópolis-SC, 2002.

\begin{tabular}{lccccc}
\hline \multicolumn{7}{c}{ Porcentagem de enraizamento } \\
\cline { 2 - 5 } \multicolumn{1}{c}{ Genótipo } & 0,1 & 0,5 & 1,0 & 2,0 & Média \\
\cline { 2 - 5 } 'Capdeboscq' & $52,0 \mathrm{bc}$ & $76,0 \mathrm{~b}$ & $100,0 \mathrm{a}$ & $96,0 \mathrm{a}$ & $81,0 \mathrm{~A}$ \\
'GF677' & $12,0 \mathrm{~d}$ & $40,0 \mathrm{c}$ & $64,0 \mathrm{bc}$ & $60,0 \mathrm{bc}$ & $56,0 \mathrm{~B}$ \\
VP411 & $48,0 \mathrm{bc}$ & $60,0 \mathrm{bc}$ & $64,0 \mathrm{bc}$ & $52,0 \mathrm{bc}$ & $44,0 \mathrm{C}$ \\
VP417 & $16,0 \mathrm{~d}$ & $36,0 \mathrm{c}$ & $56,0 \mathrm{bc}$ & $64,0 \mathrm{bc}$ & $43,0 \mathrm{C}$ \\
\hline \multicolumn{1}{c}{ Média } & $32,0 \mathrm{c}$ & $53,0 \mathrm{~b}$ & $71,0 \mathrm{a}$ & $68,0 \mathrm{a}$ & $\mathbf{5 6 , 0}$ \\
\hline CV (\%) & \multicolumn{5}{c}{26,4} \\
F(Genótipo) & \multicolumn{5}{c}{$28,4^{* *}$} \\
F(IBA) & \multicolumn{5}{c}{$28,9^{* *}$} \\
F(Genótipo X IBA) & \multicolumn{7}{c}{$2^{*}$} \\
\hline
\end{tabular}

Médias seguidas de mesma letra maiúscula na coluna (fator genótipo), minúscula na linha (fator nível de IBA) e na interação entre fatores, não diferem significativamente pelo teste SNK (5\%).

*Pd0,05 e **Pd0,01 pelo teste SNK.
TABELA 2 - Número de raízes por explante no enraizamento in vitro de quatro porta-enxertos de Prunus ('Capdeboscq', 'GF677', VP417 e VP411), referente ao uso de quatro níveis de IBA $\left(0,1 ; 0,5 ; 1,0\right.$ e 2,0 mg. $\left.\mathrm{L}^{-1}\right)$, após 15 dias de cultura in vitro. UFSC, Florianópolis-SC, 2002.

\begin{tabular}{lccccc}
\hline & \multicolumn{5}{c}{ Número de raízes } \\
\cline { 2 - 5 } \multicolumn{1}{c}{ IBA (mg.L ${ }^{-1}$ ) } & \\
\cline { 2 - 5 } 'Cenótipo & 0,1 & 0,5 & 1,0 & 2,0 & Média \\
'GF677' & $4,6 \mathrm{bcd}$ & $3,5 \mathrm{bcd}$ & $6,2 \mathrm{~b}$ & $9,6 \mathrm{a}$ & $5,9 \mathrm{~A}$ \\
VP411 & $1,6 \mathrm{~d}$ & $3,3 \mathrm{bcd}$ & $4,8 \mathrm{bcd}$ & $5,2 \mathrm{bc}$ & $3,7 \mathrm{~B}$ \\
VP417 & $2,6 \mathrm{~cd}$ & $4,2 \mathrm{bcd}$ & $3,1 \mathrm{bcd}$ & $2,4 \mathrm{~cd}$ & $3,1 \mathrm{~B}$ \\
\multicolumn{1}{c}{ Média } & $1,4 \mathrm{~d}$ & $2,2 \mathrm{~cd}$ & $3,9 \mathrm{bcd}$ & $3,5 \mathrm{bcd}$ & $2,8 \mathrm{~B}$ \\
\hline CV (\%) & $2,6 \mathrm{~b}$ & $3,3 \mathrm{~b}$ & $4,5 \mathrm{a}$ & $5,2 \mathrm{a}$ & $\mathbf{3 , 9}$ \\
F(Genótipo) & \multicolumn{5}{c}{42,5} \\
F(IBA) & \multicolumn{5}{c}{$15,6^{* *}$} \\
F(Genótipo X IBA) & \multicolumn{5}{c}{$10,1^{* *}$} \\
\hline
\end{tabular}

Médias seguidas de mesma letra maiúscula na coluna (fator genótipo), minúscula na linha (fator nível de IBA) e na interação entre fatores, não diferem significativamente pelo teste SNK (5\%).

**Pd0,01 pelo teste SNK.

A Figura 1 apresenta, para o intervalo de 0,1 a 2,0 mg. $\mathrm{L}^{-1} \mathrm{de}$ IBA, as distribuições dos pontos médios, suas respectivas equações e os coeficientes de determinação $\left(\mathrm{R}^{2}\right)$. Segundo as projeções teóricas das equações apresentadas para cada porta-enxerto, infere-se que as maiores porcentagens de enraizamento estimadas seriam obtidas na concentração de 1,4 mg.L. $\mathrm{L}^{-1}$ de IBA para os porta-enxertos 'Capdeboscq' e 'GF677'; 1,8 mg.L.' para a seleção VP417 e 1,1 mg.L.-1 para a seleção VP411, com taxas de enraizamento de $100 \%, 69,7 \%, 65,3 \%$ e $64,9 \%$, respectivamente. Observa-se que, para todos os genótipos, houve uma tendência de redução na taxa de enraizamento com o acréscimo na concentração de auxina (IBA).

\section{$\Delta$ VP417 $\diamond$ VP411 O GF677 $\square$ Capdeboscq}

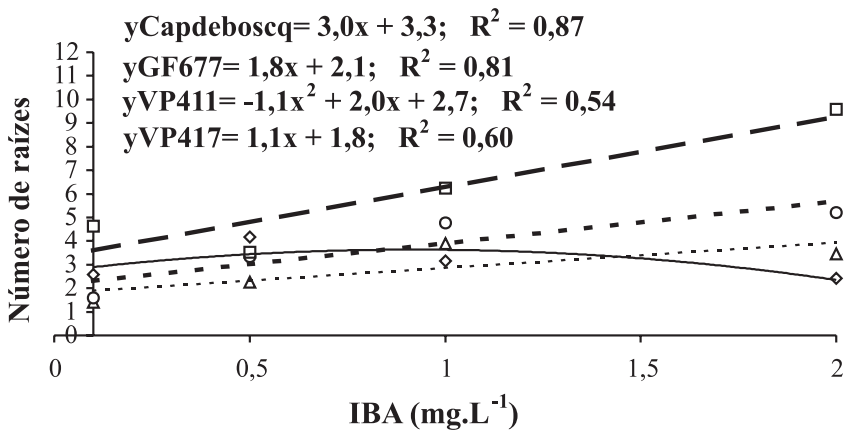

FIGURA 1 - Efeito de IBA na porcentagem de enraizamento in vitro dos porta-enxertos de Prunus cultivares Capdeboscq e GF677 e das seleções VP417 e VP411, após 15 dias de cultura in vitro. UFSC, Florianópolis-SC, 2002.

Com relação ao número de raízes, verificou-se que os níveis de IBA associados aos valores mais elevados de raízes foram de 1,0 e 2,0 mg.L $\mathrm{L}^{-1}$ para as cultivares Capdeboscq e GF677 e para a seleção VP417; 0,5 e 1,0 mg.. $\mathrm{L}^{-1}$ para a seleção VP411. A Figura 2 apresenta, para o intervalo de 0,1 a 2,0 mg.L ${ }^{-1}$ de IBA, os valores médios do efeito de IBA para todos os porta-enxertos, a equação e o coeficiente de determinação $\left(\mathrm{R}^{2}\right)$. Através das projeções teóricas das equações apresentadas para cada porta-enxerto, pode-se inferir que os porta-enxertos 'Capdeboscq', 'GF677' e a seleção VP417 apresentaram o número máximo de raízes na concentração de 2,0 mg.L.-1 de IBA, com 9,3; 5,7 e 3,9 raízes por explante, respectivamente. Já a seleção VP411 apresentou o maior número de raízes $(3,6)$ na concentração de $0,9 \mathrm{mg} \cdot \mathrm{L}^{-1}$ de IBA. 


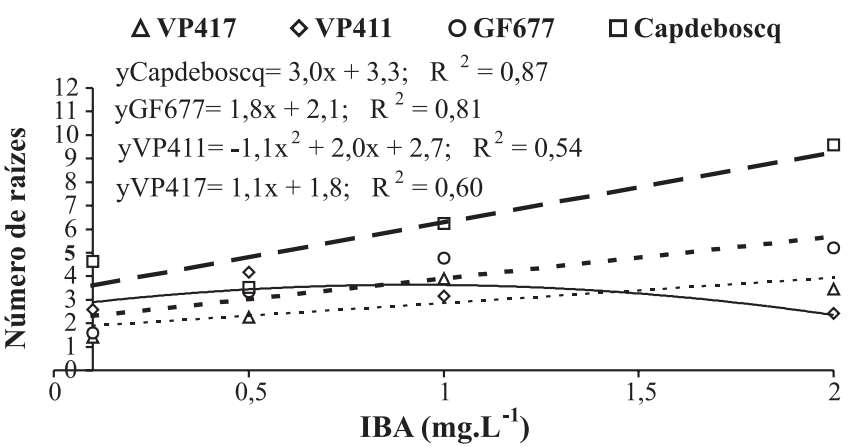

FIGURA 2 - Efeito de IBA para número de raízes por explante no enraizamento in vitro dos porta-enxertos de Prunus cultivares Capdeboscq, GF677 e das seleções VP417 e VP411, após 15 dias de cultura in vitro. UFSC, Florianópolis-SC, 2002.

Os resultados observados, em relação à porcentagem de enraizamento e ao número de raízes, são similares aos encontrados na literatura para as diferentes espécies do gênero Prunus. Pevalek-Kozlina \& Jelaska (1987) verificaram um forte efeito genotípico no enraizamento in vitro de Prunus avium, com variação de 11,0 a 90,5\% de explantes enraizados.

A capacidade de enraizamento de uma espécie ou variedade é considerada uma característica genética. Assim, Skirvin et al. (1982) obtiveram sucesso no enraizamento in vitro de pessegueiro e ameixeira, mas não para a cerejeira. Contudo, estes autores sugeriram que a capacidade de enraizamento in vitro entre as espécies poderia ser afetada positiva ou negativamente pelos constituintes do meio de cultura.
O IBA apresentou um efeito positivo no processo de enraizamento in vitro dos porta-enxertos avaliados, afetando significativamente nas diferentes fases da rizogênese: indução, diferenciação e crescimento. Estes resultados são semelhantes aos reportados por Campana et al. (1994) e Pérez-Tornero et al. (2000) para diferentes espécies de Prunus. Em Prunus mume não foi observado o desenvolvimento in vitro do sistema radicular em meio de cultura isento de auxinas (Harada \& Murai, 1996). No entanto, estes autores observaram que, com apenas $0,1 \mathrm{mg} \cdot \mathrm{L}^{-1} \mathrm{de}$ ANA, 54,5\% dos explantes formaram sistema radicular. Em Prunus cerasifera, o uso de $0,5 \mathrm{mg} . \mathrm{L}^{-1}$ de IBA resultou em uma taxa de $97 \%$ de enraizamento in vitro com a formação de 4,4 raízes por explante (Sciutti \& Morini,1993). Para o enraizamento in vitro de Prunus armeniaca, PérezTornero et al. (2000) observaram as maiores taxas de enraizamento com 2,0 mg.L $\mathrm{L}^{-1}$ de ANA e um maior número de raízes com $6,0 \mathrm{mg} . \mathrm{L}^{-1}$ de IBA.

Pelos resultados do presente trabalho, observa-se um efeito significativo da interação entre o genótipo e a concentração de IBA, confirmando a necessidade da otimização da concentração de IBA para cada genótipo. Efeitos dependentes entre a concentração de auxina utilizada e a resposta genotípica no enraizamento in vitro para espécies e variedades de Prunus são reportados por Hammerschlag et al. (1987) e Ainsley et al. (2001).

Observa-se, também, que os níveis mais elevados de IBA tendem a afetar negativamente o enraizamento e o crescimento das raízes, com a formação de calo na base das estacas (Figura 3). Estes resultados são semelhantes aos obtidos por Deklerk et al. (1997), que observaram promoção ao enraizamento e inibição das raízes em meio de cultura com IBA e ANA. Para Gebhardt (1985) e Campana et al. (1994), as auxinas favorecem na indução e diferenciação celulares, dando origem aos primórdios radiculares, porém elas não são importantes para o crescimento das raízes, fase na qual elas podem apresentar efeitos inibitórios.

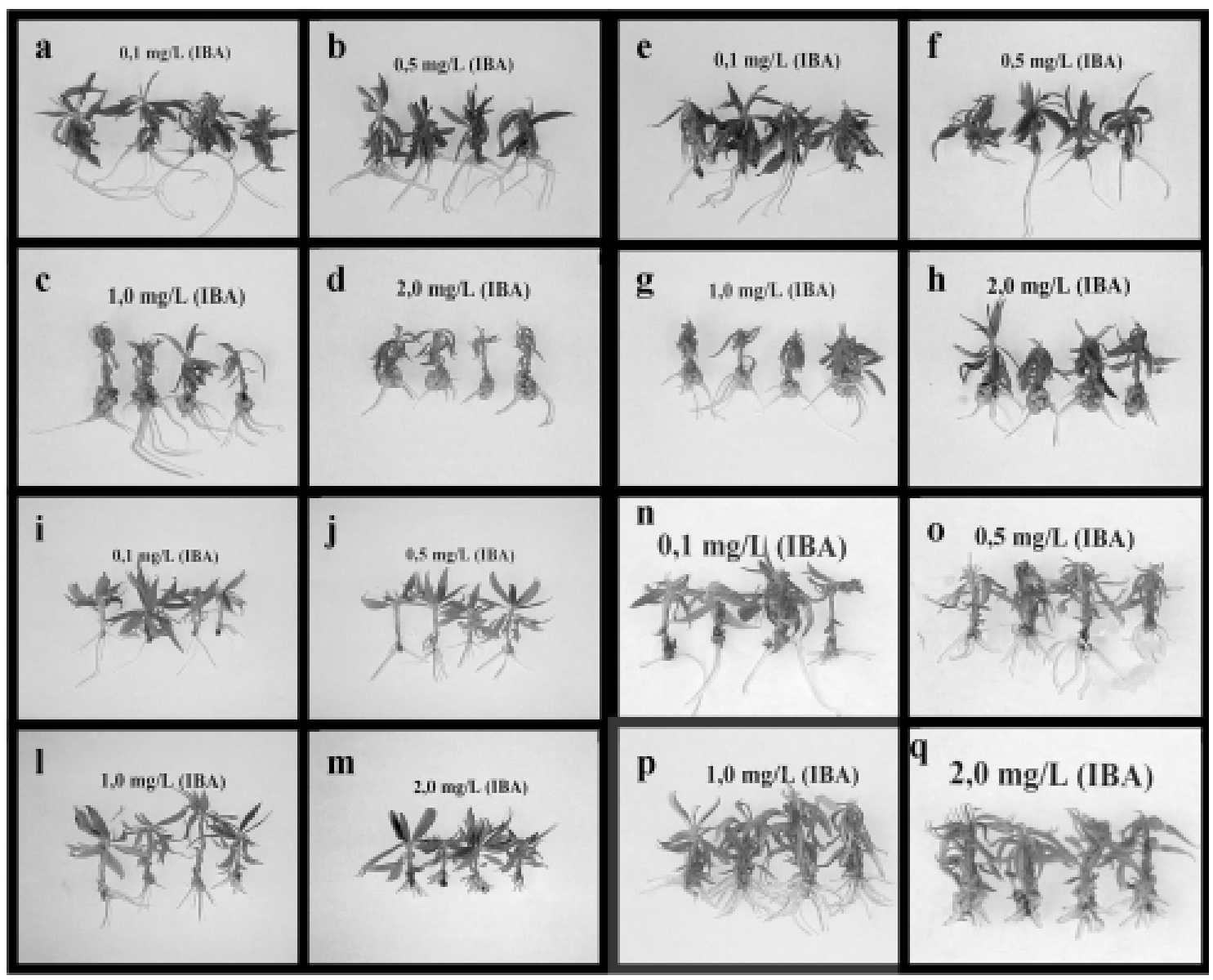

FIGURA 3 - Aspectos morfogenéticos no enraizamento in vitro dos porta-enxerto de Prunus, seleção VP417 (a, b, c, d), seleção VP411 (e, f, g, h), portaenxerto GF677 (i, j, l, m) e porta-enxerto Capdeboscq (n, o, p, q), submetidos a diferentes concentrações de IBA, após 15 dias de cultura in vitro. UFSC, Florianópolis-SC, 2002. 
Verificou-se que os genótipos apresentaram respostas variáveis às concentrações de IBA quanto ao desenvolvimento de calo na base das microestacas. As seleções VP417 e VP411 demonstraram uma intensa formação de calos na base dos explantes em resposta às concentrações de IBA maiores do que $1,0 \mathrm{mg} \cdot \mathrm{L}^{-1}$. Já, o porta-enxerto 'Capdeboscq' somente apresentou formação de calos em resposta ao nível de 2,0 mg.L-1 . O porta-enxerto 'GF677' não formou calos nas concentrações de IBA testadas (Figura 3). Segundo Filiti et al. (1987) e Campana et al. (1994), a presença de calo na base das brotações pode ser determinada por uma alta concentração de auxinas no meio de cultura.

\section{CONCLUSÕES}

1) O genótipo dos porta-enxertos avaliados influenciou significativamente nas taxas médias de enraizamento in vitro.

2) A presença de IBA foi fundamental para o enraizamento in vitro, porém o requerimento foi específico para cada genótipo.

3) O IBA influenciou positivamente na formação de raízes, mas nas concentrações mais elevadas inibiu o enraizamento e o crescimento radicular.

\section{REFERÊNCIASBIBLIOGRÁFICAS}

AINSLEY, P.J.; COLLINS, G.G.; SEDGLEY, M. In vitro rooting of almond (Prunus dulcis Mill.), In Vitro Cellular \& Developmental BiologyPlant, Wallingford, v.37, n.6, p.778-785, 2001.

CABONI, E.; TONELLI, M.G.; LAURI, P.; IACOVACCI, P.; KEVERS, C.; DAMIANO, C.; GASPAR, T. Biochemical aspects of almond microcuttings related to in vitro rooting ability, Biologia Plantarum, Prague, v.39, n.1, p.91-97, 1997.

CAMPANA, B.M.; CASTAGNARI, F.; COVATTA, F.; HENNINGS, M.; POLERO, H.J. Enraizamiento in-vitro del portainjerto Damas GF 1869 (Prunus insititia x Prunus spinosa), Revista Brasileira de Fruticultura, Cruz das Almas, v.16, n.3, p. 85-94, 1994.

DAMIANO, C.; PALOMBI, M.A. La micropropagazione 20 anni dopo: innovazioni tecniche e ottimizzazione dei protocolli delle colture in vitro. Rivista di Frutticoltura, Bologna, v. 62, n. 2, p. 48-55, 2000.

DEKLERK, G.J.; TERBRUGGE, J.; MARINOVA, S. Effectiveness of indolacetic acid, indolebutyric acid and naphthaleneacetic acid during adventitious root formation in vitro in Malus 'Jork 9', Plant Cell Tissue and Organ Culture, Dordrecht, v.49, n.1, p.39-44, 1997.

DIMASSI-THERIOU, K. In vitro rooting of rootstock GF-677 (Prunus amygdalus $\mathrm{x} P$. persica) as influenced by mineral concentration of the nutrient medium and type of culture tube sealing material, Journal of Horticultural Science, Washington, v. 70, n.1, p.105-108, 1995.

FACHINELLO, J.C. Problemática das mudas de plantas frutíferas de caroço. In: I SIMPÓSIO INTERNACIONAL DE FRUTAS DE CAROÇO: PÊSSEGOS, NECTARINAS E AMEIXAS, 1., 2000, Porto Alegre. Anais... p.25-40.

FILITI, N.; MONTUSCHI, N.; ROSATI, P. In vitro rhizogenesis: histoanatomical aspects on Prunus rootstock, Advances in Horticultural Science, Firenze, v.1, p. 34-38,1987.

GEBHARDT, K. Self-rooted sour cherries in vitro: auxin effects on rooting and isoperoxidases, Acta Horticulturae, Leuven, v.169, p. 341$349,1985$.

HAMMERSCHLAG, F.A.; BAUCHAN, G.R.; SCORZA, R. Factors influencing in vitro multiplication and rooting of peach cultivars, Plant Cell, Tissue and Organ Culture, Dordrecht, v.8, p.235-242, 1987

HARADA, H.; MURAI, Y. Micropropagation of Prunus mume, Plant Cell, Tissue and Organ Culture, Dordrecht, v.46, p.265-267, 1996.

PERELMAN, P.E.; CASO, O.H. Root formation by microshoots of Prunus insititia L., rootstock GF655/2 in an auxin free medium, ) YTON, Buenos Aires, v.69, p.65-69, 2000.

PÉREZ-TORNERO, O.; LÓPEZ, J.M.; EGEA, J.; BURGOS, L. Effect of basal media and growth regulatrors on the in vitro propagation of apricot (Prunus armenica L.) cv. Canino, Journal of Horticultural Science \& Biotechnology, Ashford, v. 75, n.3, p.283-286, 2000.

PEVALEK-KOZLINA, B.; JELASKA, S. Microclonal propagation of Prunus avium L. Acta Horticulturae, Leuven, v. 212, p .599-602, 1987.

QUOIRIN, M.; LEPOIVRE, P.; BOXUS, P. Un premier bilan de 10 années de recherches sur les cultures de méristèmes et la multiplication in vitro de fruitiers ligneux. Comptes Rendus des Recherches Agronomiques, Gembloux, p.93-117, 1977.

SCIUTTI, R.; MORINI, S. Effect of relative humidity in in vitro culture on some growth characteristics of a plum rootstock during shoot proliferation and rooting and on plantlet survival. Advances in Horticultural Science, Firenze, 7, p. 153-156, 1993.

SKIRVIN, R.M.; CHU, M.C.; RUKAN-KERNS, H. An Improved Medium for the In Vitro of Harbrite Peach. Fruit Varieties Journal, Jayson, v. 36, p. 15-17, 1982.

SOKAL, R.R.; ROHLF, F.J. Biometry. New York: W.H. Freeman and Company, 1995.

Rev. Bras. Frutic., Jaboticabal - SP, v. 25, n. 2, p. 293-296, Agosto 2003 